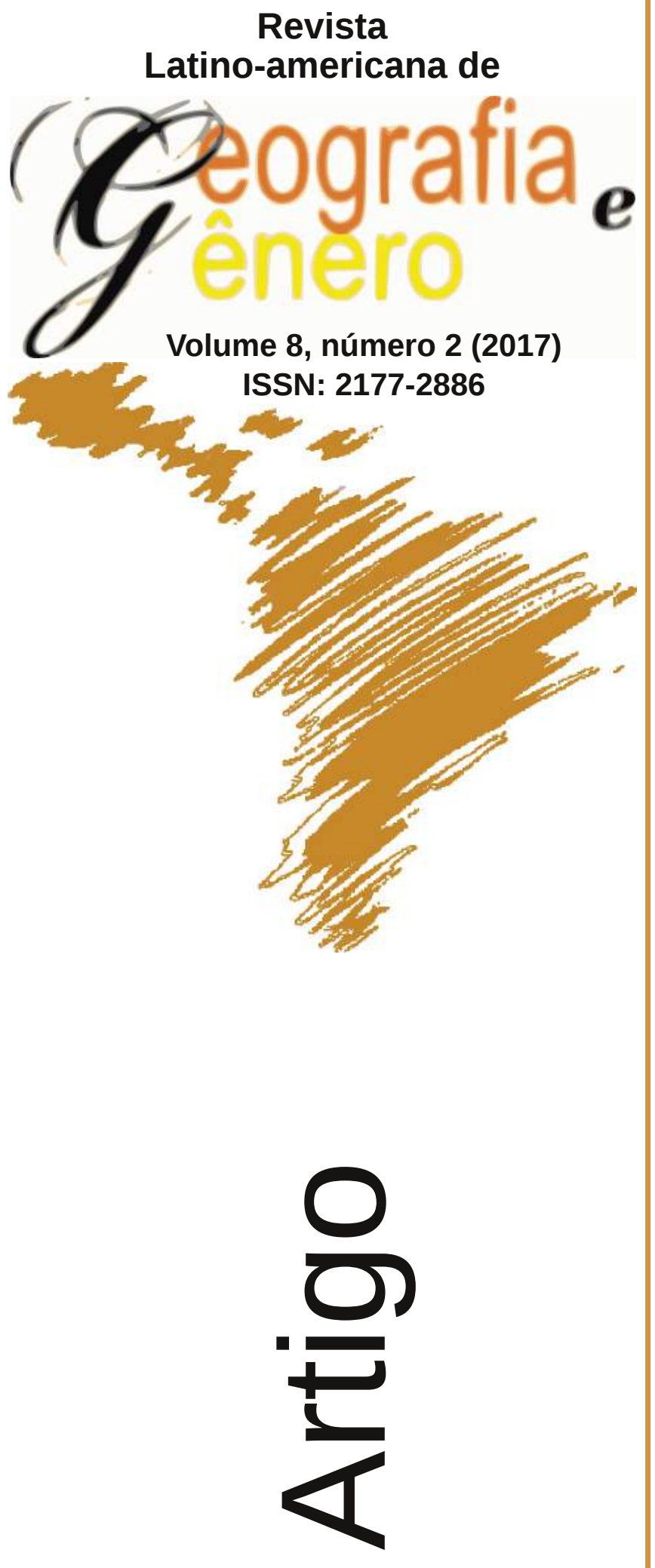

Hijab e Identidade: as Formas de Empoderamento Feminino através da Territorialização do Corpo no Islã

Hijab e Identidad: las Formas de Empoderamiento Femenino a través de la Territorialización del Cuerpo en el Islam

Hijab and Identity: Women's Empowerment through Territorialization of the Body in Islam

\author{
Karina Cruz Arroyo \\ Universidade do Estado do Rio de Janeiro - \\ Brasil \\ kary_arc@yahoo.com.br
}

Como citar este artigo:

ARROYO, Karina Cruz. Hijab e Identidade: as Formas de Empoderamento Feminino Através da Territorialização do corpo no Islã. Revista Latino Americana de Geografia e Gênero, v. 8, n. 2, p. 7896, 2017. ISSN 2177-2886.

Disponível em:

http://www.revistas2.uepg.br/index.php/rlagg 


\title{
Hijab e Identidade: as Formas de Empoderamento Feminino através da Territorialização do Corpo no Islã
}

\author{
Hijab e Identidad: las Formas de Empoderamiento Femenino a través de la \\ Territorialización del Cuerpo en el Islam
}

\author{
Hijab and Identity: Women's Empowerment through Territorialization of the \\ Body in Islam
}

\section{Resumo}

A contextualização das formas de empoderamento feminino é uma questão premente quando se observam os discursos acerca do que seria o conceito universalmente válido de liberdade sobre as condutas sociais de empoderamento apreendidas como legítimas. As variações semânticas e culturais são extensas e as vozes dos coletivos femininos exponenciados são objeto de análise da Geografia Cultural, pois perpassam a cultura, se espacializam e se flexibilizam às polivocalidades locais. Nesse sentido, através de uma bibliografia sócioantropológica e geográfica e da pesquisa de campo etnogeográfica, se ressaltam e contextualizam as vozes femininas no Islam e a compreensão de como as mulheres muçulmanas que vivem no Brasil compreendem o uso do hijab através de uma interpretação geográfica da territorialização do corpo no cotidiano.

Palavras-Chave: Islã ; Território; Territorialidade; Vestimenta Islâmica; Empoderamento Feminino.

\section{Resumen}

La contextualización de las formas de empoderamiento femenino es una cuestión apremiante cuando se observan los discursos acerca de lo que sería el concepto universalmente válido de libertad sobre las conductas sociales de empoderamiento entendidas como legítimas. Las variaciones semánticas y culturales son extensas y las voces de los colectivos femeninos son objeto de análisis de la Geografía Cultural, ya que atraviesan la cultura, se espacializan y se flexibilizan en las polivocalidades locales. En este sentido, a través de una bibliografía socioantropológica y geográfica y de la investigación de campo etnogeográfica, se resaltan y contextualizan las voces femeninas en el Islam y la comprensión de cómo las mujeres musulmanas que viven en Brasil comprenden el uso del hijab a través de una interpretación geográfica de la territorialización del cuerpo en lo cotidiano.

Palabras-Clave: Islam; Territorio; Territorialidad; Vestimenta Islámica; Empoderamiento Femenino. 
Hijab e Identidade: as Formas de Empoderamento Feminino Através da

Territorialização do corpo no Islã

\section{Abstract}

Contextualizing female empowerment with its several forms is a pressing issue when one observes the discourses about what would be a universally valid concept of freedom concerning empowerment social behaviors that are considered as legitimate. Both semantic and cultural variations are extensive and the voices of the exponential feminine collectives are object of analysis of the Cultural Geography, since they pass through culture, spatialize themselves and become flexible under local polyvocalities. In this sense, by means of a socioanthropological and geographic bibliography and of an ethno-geographic field research, women's voices in Islam are emphasized and contextualized as well as the comprehension of how Muslim women living in Brazil understand the use of hijab, through a geographical interpretation of the territorialization of the body in everyday life.

Keywords: Islam; Territory; Territoriality; Islamic Garment; Female Empowerment.

\section{Introdução}

A constituição do corpo é, sobremaneira, uma construção social. O embasamento biológico que determina categoricamente a inclusão do indivíduo em determinado gênero ganha um desfecho completo quando o sujeito se autodetermina. As vozes, que daí surgem, começam a se distanciar do padrão ora imposto, simplista e dual da concepção biológica cristalizada e hermética do que seja ser mulher e, principalmente, sob quais condições ela está na condição de um ser social autônomo e empoderado e, ainda, em qual temporalidade e territorialidade está inserida. Nem sempre essas condições são lineares e constantes. Há uma dinâmica cultural que torna flutuante as variáveis de poder. No desenvolvimento sociopolítico e cultural do sujeito, há uma paulatina diferenciação que exponencia a qual grupo cultural a mulher, objeto desta análise, se insere. A partir de então, se observa que alguns coletivos femininos são, muitas vezes, sobrepostos como vulneráveis e reprimidos, sem, no entanto, se apreender corretamente a leitura dada pelo próprio grupo ao seu simbolismo material. Nesse sentido, a pesquisa acerca da vestimenta religiosa é relevante e pertinente ao debate acadêmico quando pensamos em mobilidade social, marcas identitárias, simbolismo e territorialidades. Neste ínterim, o diálogo travado entre as Ciências Humanas em geral, e entre a Geografia Cultural pós 1980 e a Antropologia Cultural, em particular, permitem construir uma teia de significados complementares que levam a êxito à compreensão da construção identitária através da vestimenta religiosa, capaz de territorializar o corpo e imprimir significados às performances cotidianas. Permitir essa simetria, reversibilidade e reflexividade na observação da mulher muçulmana, nos coloca em uma plataforma mais simétrica que, portanto, analisa como a racionalidade de um sistema complexo influencia no comportamento social. Na Geografia, esse enfoque na religião ganha relevância, pois, de acordo com a geógrafa Joseli Maria Silva (2009), a extraordinária importância dos movimentos de mulheres ao longo de décadas e a força do feminismo latino-americano, um dos maiores do mundo, combinando reflexões teóricas e o ativismo político, marcado ainda, pelo compromisso com a melhoria da sociedade através de relações de gênero, 
passam despercebidos pela Geografia brasileira (2009). Essa afirmação nos permite constatar a necessidade de trabalhar as questões de gênero de maneira mais acurada na Geografia Cultural, dedicando especial atenção às particularidades da religião no trato do tema, justificando a relevância do desenvolvimento deste artigo.

Iniciamos nas linhas seguintes uma resposta ao questionamento inicial acerca do entendimento do uso do hijab por uma perspectiva geográfica da territorialização do corpo no cotidiano. No primeiro capítulo: $O$ corpo e sua territorialidade: simbolismos, os conceitos caros à geografia como território, territorialidade e territorialidade religiosa passam por uma revisão de literatura para que se possa construir o corpo teórico que sustentará a pesquisa de campo. O corpo e seu simbolismo são abordados como objetos na geografia a partir de determinados marcos temporais, traçando-se uma cronologia com alguns autores de outras áreas que contribuíram para a Geografia Humana no estudo das corporeidades e suas performances. Estabelecem-se relações sígnicas e relacionais entre os conceitos geográficos e sua representação empírica para que, a partir de uma epistemologia geográfica, se compreenda a construção de territorialidades através de, e a partir de uma vestimenta religiosa, o geossímbolo hijab. No segundo capítulo: A semiografia $e$ o método, a pesquisa ganha detalhamento e densidade ao ser descrita a metodologia empregada, os objetivos e a justificativa pela etnogeografia, bem como sua origem e utilização. As interlocutoras são apresentadas a partir de uma descrição biográfica com cuidado pela privacidade dos dados pessoais, visto que o anonimato é garantido na pesquisa de campo quando lidamos com comunidades que prezam pela reserva de sua imagem. Ainda neste capítulo, as conclusões alcançadas no campo são descritas e exploradas com enfoque a dois diálogos intencionalmente selecionados.

Cabe a nós, agora, iniciar o estudo e a reflexão geográfica aqui propostas.

\section{O Corpo e Sua Territorialidade: Simbolismos}

O conceito de território sofreu, ao longo das últimas três décadas, novas releituras, em grande medida, graças à Geografia Cultural que permitiu um aporte teórico mais abrangente e carregado de subjetividade que deu conta de descrever e caracterizar a construção do espaço como algo intrinsecamente humano, dedicando ao homem a responsabilidade de semiografar os espaços e imprimir sua cultura, demarcando e modelando a paisagem. Sob este aspecto, tornou-se possível compreender o indivíduo como agente espacial que territorializa seu fluxo, sua performance (SCHECHNER, 2006) no lócus escolhido. Todas essas categorias espaciais passam a ser dependentes e passíveis de modificação. O sujeito, enquanto unidade móvel e cultural, é capaz de transformar seu corpo em uma unidade territorial, um território móvel per se. A partir do instante em que este corpo apresenta um comportamento espacial intencional e expressivo, dotando-lhe de particularidades individuais e exclusivas, torna-se uma territorialidade naturalmente móvel, visto que o corpo movimenta-se semiografando os espaços constantemente e ininterruptamente. Para levar a cabo essa expressividade espacial, o indivíduo lança mão de artefatos corporais simbólicos, dentre eles, a vestimenta religiosa feminina, o 
objeto de análise deste artigo. Para melhor embasar estes aspectos conceituais, que desencadeiam uma análise mais complexa sobre a vestimenta, lê-se na geografia de Haesbart (2006) a valorização do processo humano espacial na produção simbólica, priorizando a dimensão ainda mais subjetiva para a compreensão da formação das espacialidades, o que nos impulsiona, portanto, a analisar os conceitos geográficos com os quais trabalharemos neste artigo apoiados em pesquisas anteriores que relevam a dimensão cultural na análise espacial. Partamos, assim, para a análise conceitual inicial de território e territorialidade.

Ao atribuir ao conceito de territorialidade três ingredientes espaciais, Soja (1971) diferencia qualitativamente os espaços de ação antrópica. O sentido de identidade espacial, de exclusividade e da compartimentação da interação humana são atributos que permitem o controle do espaço através da demarcação, interdição e dominação, caracterizando a territorialidade. Já para Sack (1986), a territorialidade é um comportamento humano espacial, é uma práxis observável e compartilhada, uma expressão de poder que não intencional e não agressiva, apenas se constitui em uma estratégia humana para afetar, influenciar e controlar pessoas, fenômenos e relações no uso social do espaço. Já Hall (2005), através do conceito de proxemia, produz um refinamento da territorialidade biocenótica que define uma espécie de envoltório ou cabina invisível que delimita espaços individuais como territórios portáteis individuais com limites flexíveis de acordo com a percepção espacial, constituindo-se em um componente cultural especializado de caráter restrito. Como ressalta o autor, tudo que o homem faz esta relacionado com sua experiência espacial, e o significado que atribuímos ao espaço que regulamenta o nosso desempenho está profundamente relacionado com produção simbólica.

Territorialidade religiosa, por sua vez, significa o conjunto de práticas desenvolvido por instituições ou grupos no sentido de controlar um dado território, onde o efeito do poder do sagrado reflete uma identidade de fé e um sentimento de propriedade mútuo. A territorialidade é fortalecida pelas experiências religiosas coletivas ou individuais, estabelecendo a relação simbólica que existe entre cultura e espaço (ROSENDAHL, 2012). Território e territorialidade representam escalas de complexidade na gestão do espaço, iniciando como lugar de característica topofílica (TUAN, 1983), evoluindo para o território com a elaboração de códigos de agrupamento burocráticos e definição de fronteiras com características jurídico-políticas, culminando no desenvolvimento de estratégias de influência e controle, observados nas territorialidades. Ambos são artefatos simbólicos, imateriais e classificatórios.

O território torna-se, então, um geossímbolo (BONNEMAISON, 1997) entendido como um artefato material com referenciamento espacial dotado de centralidade, que aponta ausências e conecta um grupo a seu objeto ou lugar de memória. Pode ser um objeto, uma canção, um lugar delimitado, um acidente geográfico, desde que ele possua imbricado em sua existência um valor simbólico atemporal e contínuo.

Encontramos, portanto, aqui a definição do $h i j a b^{1}$ ou véu islâmico feminino

1 Hijabe ou hijab (do árabe: باجح, translit. hijāb, significa literalmente cobertura, podendo sofrer variação e utilizado como "esconder o olhar". (Motahari, 2008, p. 124).

Karina Cruz Arroyo 
na Geografia Cultural: um geossímbolo que conecta a muçulmana a seu grupo, dotando-lhe de referenciamento e instrumentalização social.

Logo, a relação geográfica entre territorialidade e geossímbolo pode ser compreendida através de sua projeção sígnica: corpo e hijab. Enquanto o corpo se limita e define através da cultura que lhe é empregada, desenvolvendo um comportamento intencional e contextualizado, exclusivo e compartimentado características da definição de territorialidade, passa-se então a identificar no corpo, portanto, estas marcas de territorialidade, principalmente quando ele atua como vetor de técnicas corporais ${ }^{2}$ (MAUSS, 1974) específicas, podendo ser abordadas como um fato social total, ou seja, como um fenômeno que engloba diferentes dimensões da experiência social e individual, aludindo ao enfoque antropológico destinado ao corpo como um constructo social. Corpos investidos de agência e subjetividade produzem e representam uma dada cultura, confirmando de maneira peremptória o corpo como territorialidade, espaço exclusivo de poder e representação. Articulando ainda mais o entendimento sobre o corpo e o hijab, alçados neste artigo como categorias de reflexão geográfica, podemos falar de representação territorial através dos geossímbolos, que, já definidos como objetos centrais de conexão e memória, funcionam como elemento obrigatório nas territorialidades religiosas, dada sua íntima relação entre territorialidade e cultura. Seguindo, dessa forma, o raciocínio de que territorialidades são espaços de poder dotados de exclusividade e limite e os geossímbolos são objetos referenciais que semiografam os espaços e lhes denotam memória e identidade, produzindo a cultura, compreende-se então o porquê do corpo feminino instrumentalizar o hijab como objeto de identidade religiosa, referenciamento e memória que o distingue do meio homogêneo, não religioso (ELIADE, 1992).

A categoria de geossímbolo, no entanto, não encerra a definição geográfica e as possibilidades de apropriação cultural do hijab. Entendido como uma vestimenta religiosa, ainda carece de outro olhar sob o viés geográfico que poderá ser atribuído pelo geógrafo Carlos Eduardo Santos Maia (2015), que se dedica ao tema das vestimentas, objeto de destaque na geografia clássica, e especialmente abordado, na geografia francesa, outrora explorado como objetos de pesquisa por Vidal de La Blache, Sorre, Deffontaines e Ratzel. O hijab torna-se objeto relevante na geografia quando entendido para além do significado lato sensu de vestimenta, e sim, na concepção de Santos Maia (2015, p. 196) que compreende os diversos usos e apropriações possíveis:

Nestas diferentes definições ressalta-se que vestimentas cobrem o corpo, mas, ao fazê-lo, ganham significados maiores que o de simples "cobertura" e expressam status, classes, grupos etários, identificações, gostos e costumes.

A tradição francófona clássica, de inserir as vestimentas no contexto do gênero de vida e vê-las como objeto de estudo, foi seguida por Deffontaines,

2 Os modos de caminhar, dormir, escavar, nadar, parir, sentar e comer que variam de uma cultura para outra. In: MAUSS, Marcel. As técnicas corporais. In: Sociologia e Antropologia. Vol 2. São Paulo: EDUSP, 1974, p. 209-233. 
que teve enorme impacto na institucionalização da geografia acadêmica brasileira. No trabalho intitulado L'Homme et L'Hiver au Canada, o autor descreveu a influência do inverno na geografia das vestimentas no Canadá colonial, expondo como hábitos franceses foram adotados e adequados àquela realidade (SANTOS MAIA, 2015). A objetividade para tratar desse temário, desde a geografia clássica alemã de Ratzel, inicialmente associando uma preocupação da geografia das vestimentas à economia industrial têxtil, foi paulatinamente substituída pelos usos e significados atribuídos às vestimentas, passando de um estudo de viés geográfico-econômico para um estudo geográfico-simbólico.

Nesse sentido, a Geografia Cultural contemporânea sofisticou suas categorias de análise e fala em linguagem das vestimentas como instrumentos que nos possibilitam ler determinadas espacialidades e, ainda, entendê-las como definidoras de espaços-tempos. Neste estudo aqui desenvolvido, o hijab é uma linguagem traduzida como instrumento individual identitário que pode ser lido como geossímbolo religioso contemporâneo, presente nas comunidades islâmicas brasileiras. $\mathrm{O}$ empoderamento feminino advindo da instrumentalização da vestimenta religiosa sucede a eficácia do hijab como signo identitário. Uma vez que a mulher se utilize deste geossímbolo religioso para a consecução de sua agência religiosa, social ou política, estará desenvolvendo sua corporeidade e demarcando sua territorialidade em uma relação subjetiva contínua e espacializada de poder e influência.

A discussão sobre corpo e corporeidade na geografia cultural é recente e expressiva e sorveu, em grande medida da antropologia cultural, das formas expressivas e da etnocenologia ${ }^{3}$, onde podemos citar alguns exemplos com os trabalhos de Mauss (1974), Turner (1988), Barba (1995), Bião (1998), Camargo (2002), Schechner (2006) e Le Breton (2007), e da fenomenologia com Husserl (1991), Merleau Ponty (1945) e Sartre (1964), destacando parte de seu arcabouço teórico. Hoje, a discussão geográfica sobre corpo, corporeidade e cultura, expressa nas vestimentas e nos gêneros de vida, atingiu um patamar autônomo na Geografia Cultural que pode ser apreciado através de uma vasta gama de trabalhos publicados sobre o tema.

A discussão sobre o corpo na geografia é inequívoca enquanto o define como agente espacializado e autônomo (embora, em certa medida, produto do seu meio), se espraia e semiografa os espaços. Já quando em determinado contexto, constrói lugares de pertencimento e na complexidade da gestão desse espaço culmina nas territorialidades móveis pelo gesto intencional, tanto no âmbito sagrado quanto profano. Nesta simbiose profunda, entre corpo e espaço, se compreende a ideia de mobilidade territorial, visto que o corpo culturalizado é um agente móvel que longe de essencializar sua cultura, a reconstrói entre trânsitos, contatos e permutas (ARROYO, 2016).

A corporeidade definida por Le Breton traz à concepção do corpo a qualidade de agência, de instrumento relacional com o mundo, corroborando a visão geográfica de que todo corpo se insere em um determinado espaço-

3 Disciplina criada na França, em 1996, é o estudo das 'técnicas corporais cotidianas' e 'extracotidianas' em sua relação com a cultura. Ver mais em BIÃO, Armindo J. C. Etnocenologia, uma introdução. In: GREINER, Christine; BIÃO, Armindo. (Org.) Etnocenologia. Textos Selecionados. São Paulo: Annablume/PPGAC/GIPECIT, 1998. 
tempo e representa a extensão de sua cultura simbolicamente. Vejamos:

Pela corporeidade, o homem faz do mundo a extensão de sua experiência; transforma em tramas familiares e coerentes, disponíveis à ação e permeáveis à compreensão. Emissor ou receptor, o corpo produz sentidos continuamente e assim insere o homem, de forma ativa, no interior de dado espaço social e cultural (LE BRETON, 2007, p. 8).

Corpo e corporeidade são conceitos centrais para a compreensão do uso, apropriações e instrumentalizações da vestimenta religiosa enriquecendo o debate geográfico.

Torna-se importante, a partir desse momento, após a apresentação e análise dos conceitos geográficos que embasam a proposta de análise deste trabalho, direcionar nossa atenção ao significado religioso do hijab através do Qur'an ${ }^{4}$. Cobrir-se é, antes de tudo, uma prescrição religiosa não compulsória, como se observa no Livro sagrado do Islã:

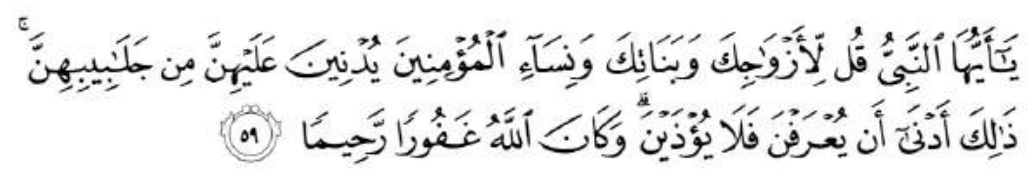

(Qur'an 33:59)

Ou ainda:

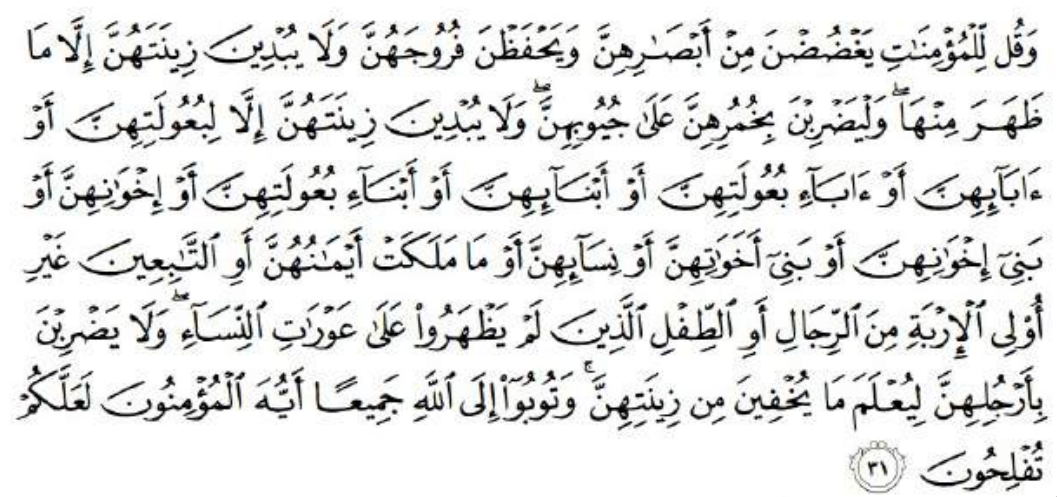

(Qur'an 24:31)

A ideia comumente apresentada de uma imposição patriarcal ao uso da cobertura é muito mais uma questão cultural do que um dever religioso. $\mathrm{Na}$ época da expansão e difusão do Islã a partir do século VIII d. C., as mulheres que apoiaram a missão do profeta Muhammad passaram a ser porta-vozes, educadoras e difusoras da mensagem islâmica. A privacidade do corpo e da

5 "Profeta Ó, dize a tuas esposas, tuas filhas e às mulheres dos fiéis que (quando saírem) se cubram com as suas mantas; isso é mais conveniente, para que distingam das demais e não sejam molestadas; sabei que Deus é Indulgente, Misericordiosíssimo." (Qur'an 33:59). Tradução do autor.

6 "Dize às fiéis que recatem seus olhares, conservem seus pudores e não mostrem os seus atrativos, além dos que (normalmente) aparecem; que cubram o colo com seus véus e não mostrem seus atrativos" (Qur'an 24:31). Tradução do autor. 
imagem, em geral, se devia ao assédio sofrido por essas mulheres no início da Revelação (MOTAHARI, 2008). A partir de então, o hijab foi visto como um artefato em prol da preservação e do recato com a finalidade de salvaguardar a imagem e a modéstia e, consequentemente, a sexualidade, práticas recomendadas às mulheres, evidenciando que as prescrições religiosas surgiam de acordo com o desenvolvimento e expansão religiosa.

Cabe ressaltar que a preservação da sexualidade é um fator derivado da justificativa principal do uso do hijab. Neste ponto, busca-se frisar que o controle das pulsões e dos desejos se dá no campo da consciência e do contexto cultural e não no uso de alguma vestimenta religiosa. As questões que levam à decisão de seu uso, no Brasil, especificamente no campo escolhido, na cidade de São Paulo, dentre as informações recolhidas, que veremos mais adiante, são, em sua quase totalidade, derivadas de um desejo pessoal e na relação direta entre a mulher e sua cosmologia religiosa. É uma relação dual, íntima e independente de hierarquizações e imposições de qualquer natureza. $\mathrm{Na}$ teoria jurisprudencial ${ }^{7}$ apresentada claramente através do árabe original, é declarada que a igualdade de gêneros diferencia-se da uniformidade. Igualdade e uniformidade são categorias utilizadas no Islã nas cinco escolas jurisprudenciais majoritárias ${ }^{8}$ que justificam todo o Tratado dos Direitos, elaborado ao longo dos vinte e três anos da revelação do Livro Sagrado, busca a igualdade no juízo de valor e na atribuição das penalidades sem diferenciação de gênero. A uniformidade com o gênero masculino, entretanto, é condenada (MOTAHARI, 2008). Neste caso, a uniformidade refere-se à performance cotidiana (BARBA, 1995), visível aos sentidos, à diferenciação social e biológica e, principalmente, aos papéis sociais. Para análise de seu papel social na geografia, o sujeito deverá ser observado sob três dimensões indissociáveis e complementares: identidade, espaço e tempo. $\mathrm{O}$ sujeito espacializado, e em determinada temporalidade, irá desempenhar uma representação social que, longe de ser evidente, previsível e linear, apresenta uma versão de determinado comportamento voluntário e premeditado (GOFFMAN, 1980). Como diz o psicólogo romeno Moscovici:

Nesse sentido, uma representação é ao mesmo tempo uma imagem e uma textura da coisa imaginada que manifesta não apenas o sentido das coisas que coexistem, mas também preenche lacunas - o que é invisível ou está ausente dessas coisas (MOSCOVICI, 2003, p. 184).

Pensando na representação como uma imagem densa das coisas, onde se inclui não só a linguagem verbal, mas, também, a não verbal, a cultural visual, o simbolismo visível e o latente, o comportamento restaurado (SCHECHNER,

7 A jurisprudência islâmica é dividida em cinco escolas ou Maddahib: Maliki, Shafi'i, Hanafi, Hanbali e Jaffaryah. Essas escolas carregam o nome de seus fundadores e jurisprudentes. As fontes principais do Direito Islâmico são em ordem hierárquica: o Qu'ran (Livro Sagrado), a Sunnah (ditos e atos do profeta transcritos, código comportamental ou tradições), qiyas (analogia) e ijma (consenso)

8 Existem diversas escolas ou métodos de interpretação. As mais conhecidas são as cinco escolas majoritárias: Habali, Hanafi, Sha'afi, Maliki e Jaffaryia. 
2006) $)^{9}$ e o fortuito, iremos analisar a instrumentalização do hijab pelas mulheres muçulmanas.o

\section{A Semiografia e o Método}

A partir deste momento, munidos teoricamente, após a revisão e análise dos conceitos geográficos, podemos passar à reflexão da instrumentalização do hijab pela mulher muçulmana em uma dada comunidade, após uma longa e densa pesquisa de campo geográfica, ao longo de dois anos. A produção e gestão de códigos sociais, proporcionada por uma vestimenta que reflete uma identidade de resistência (NORTON, 2000), nos inquietou e nos orientou para a coleta de informações e interpretações durante os contatos dialógicos.

Portanto, pouco nos serve uma observação através de uma plataforma standart, sem uma imersão e participação profunda no cotidiano do grupo estudado. Ainda nesse sentido, compreender o discurso emancipatório de empoderamento e autonomia das mulheres muçulmanas perpassa nossa apreensão visual e auditiva, e adentra as camadas de significados impressas no ato elocutório, na exteriorização material da cultura, nas práticas sociais e na dinâmica das instituições do grupo. Isso nos aponta continuamente a um método de pesquisa etnogeográfico (HOLZER, 2008).

Já em 1947, em discurso na Association of American Geographers (AAG), John Kirtland Wright propôs à Geografia o estudo das 'terras incógnitas pessoais', pressupondo a necessidade de uma avaliação não sistemática, objetiva ou cartesiana sobre os lugares já explorados quantitativamente. Seria, então, necessária uma geosofia histórica, autorizando o estudo do conhecimento geográfico por outras áreas que agregassem a subjetividade acadêmica e pessoal à geografia. (WRIGHT, 1947). Só com Lowenthal, em 1961, após um amadurecimento das possibilidades de análise no campo, e através da geosofia, abarcaria-se uma nova filosofia metodológica com variadas formas de observação, pautando-se na descrição rigorosa do mundo vivido da experiência humana e, com isso, através da adoção da intencionalidade, reconheceria a essência das estruturas perceptivas, incluindo o consciente e o inconsciente e, portanto, o deliberado e o fortuito (RELPH, 1976; BUTTIMER, 1974 apud HOLZER, 2008). Finalmente, com 'Humanistic Geography' (TUAN, 1976), definia-se uma orientação humanista para a geografia. Para Tuan, o objetivo do novo campo disciplinar não era se deter na exploração de um tema único, mas, de fazer uma nova leitura de todos os temas geográficos, de construir o conhecimento científico, de modo crítico, procurando na filosofia um ponto de vista para a avaliação dos fenômenos humanos. No referido artigo foram indicados cinco temas de interesse da geografia humanista que, para o autor, estavam além da metodologia científica. Eram eles: o conhecimento geográfico, território e lugar, aglomeração e privacidade, modo de vida e economia e, finalmente, religião (ARROYO, 2016).

9 Comportamento restaurado: 'porções recombinadas de comportamentos previamente vivenciados' (SCHECHNER, 2006). 
Para realizar a etnografia na qual nos propusemos, usufruímos da invisibilidade que a comunidade religiosa nos proporcionou, visto que fui partícipe das reuniões religiosas (salat jumah e majlis de Ashura) ${ }^{10}$ na condição de membro antes de ser reconhecida como pesquisadora. A despeito dos exercícios de internalização e práxis conceituais de reflexividade e simetria, indispensáveis a uma metodologia voltada à etnogeografia, foi-nos possível concluir a análise, tendo em vista a liberdade intelectual e sensitiva, além das peculiaridades da filosofia fenomenológica, próprias do método de pesquisa na geografia humanista.

$\mathrm{Na}$ Geografia Cultural, a questão metodológica foi abordada por Gillian Rose (2007) em seu livro Visual Methodologies an Introduction to the Interpretation of Visual Materials, apoiando-se na premissa baseada na necessidade de que cientistas sociais devem desenvolver a capacidade de compreender $\mathrm{e}$ interpretar as imagens, porque elas constituem, na contemporaneidade, importantes meios, através dos quais a vida cotidiana se desenvolve, substituindo as palavras como um todo e é por esta razão que o interesse pelo campo da cultura visual tem se expandido e, com ele, emergem as tensões e debates nas ciências interessadas em tal abordagem. Argumenta, ainda, que o método contempla tanto os aspectos de composição da imagem como as relações sociais que a envolvem. A utilização da semiologia como método de interpretação de imagens auxilia na compreensão de significados e códigos que geram determinadas tendências, ou seja, os códigos dominantes, através dos quais, as imagens são interpretadas. Assim, torna-se metodologia imprescindível na análise do humano e, principalmente, aplicável à compreensão de símbolos religiosos e suas apropriações, objeto deste artigo.

A Geografia das Emoções já abordou a questão do hijab, o trabalho de MacGinty intitulado Emotional geographies of veiling: the meanings of the hijab for five Palestinian American Muslim women, em 2013, em que desenvolve uma análise geográfica das dimensões das veiling pratices ${ }^{11}$ ou geografias emocionais do véu (MACGINTY, 2013, p. 683), em que a partir de um estudo de caso, com cinco muçulmanas americanas-palestinas, trata das questões identitárias a partir dos estereótipos demonizadores do Isla, vinculadas pelo mundo ocidental. Isso demonstra que a Geografia Cultural já se preocupa com as questões de gênero, identidade e diferença, embasando-se a uma epistemologia geográfica.

Na nossa etnogeografia, desenvolvida ao longo dos anos de 2013 a 2015, a questão do gênero surgiu de uma inquietação no campo, acerca da indumentária utilizada nos rituais de Ashura $^{12}$, objeto de dissertação na área da Geografia Cultural em que trabalhamos com a comunidade xiita. Partimos, assim, de uma observação participante completa - etnogeográfica - como

10 Oração congregacional às sextas feiras e celebrações anuais de luto em que se relembra o martírio de Ima Hussein, neto do Profeta do Isla, Muhammad na Batalha de Karbala.

11 Práticas do véu.

12 Celebração do martírio do neto do Profeta Muhammad, Imam Hussein Inb Ali abu Taleb, martirizado na Batalha de Karbala, Iraque, em 680 d. C. 

pesquisa bibliográfica e seu arcabouço teórico, construindo um primeiro olhar sobre o assunto.

Esta pesquisa baseou-se nas definições de Lapassade (1991), que descreve a observação participante como o trabalho de campo no seu conjunto, desde a chegada do investigador ao campo, quando inicia as negociações que lhe darão acesso a ele, até ao momento em que o abandona, depois de uma estada longa. Enquanto presentes, os observadores imergirão, pessoalmente, na vida dos locais, partilhando as suas experiências.

Nesta pesquisa incluí-me como pesquisadora na categoria de observadora participante completa por oportunidade ${ }^{13}$. Sobre a espacialidade e a temporalidade da pesquisa, iniciou com os diálogos de maneira pessoal e constante com as interlocutoras durante as salat Jumma ${ }^{14}$, e durante as celebrações de Ashura, em 2014 e, ainda, nos seus locais de trabalho como convidada e amiga. A observação da mulher muçulmana se deu na Masjid ${ }^{15}$ Mesquita Muhammad Mensageiro de Deus, na cidade de São Paulo, situada na Rua Elisa Witacker, 17, Brás, criada em 1987 e administrada pela Associação Religiosa Beneficente Islâmica do Brasil (ARBIB) ${ }^{16}$. Imbuída do espírito de salvaguardar a tradição xiita, minoria nas migrações pós-1980, fundada por libaneses do sul.

Tive como interlocutoras três mulheres pertencentes à comunidade muçulmana xiita do Brás ${ }^{17}$. A primeira é D. B., Uma muçulmana brasileira revertida, ou seja, muçulmana por decisão individual, advogada, 45 anos; a segunda, I. K., uma descendente de libaneses, nascida no Brasil, mas, 'árabe' por autoatribuição, professora, 31 anos; e a terceira, F. M., uma libanesa imigrante, recém-chegada em virtude de um casamento com um primo descendente de libaneses e brasileiro, estudante universitária, 23 anos. A escolha dessas três mulheres adeptas do hijab, foi estratégica do ponto de vista metodológico. Foi uma tentativa de comprovação empírica dos questionamentos levantados antes da ida ao campo e explicitadas no capítulo anterior.

Durante os diálogos desenvolvidos no campo, os que mais ganharam relevância, exatamente por irem de encontro aos meus questionamentos acerca das questões geográficas acerca do geossímbolo, vestimentas religiosas e da dinâmica de poder das territorialidades, foram os que aludiam às várias personagens femininas como 'virtuosas' enquanto usavam seus hijabs. A preferida é Maria, mãe de Jesus ou Mariam, na terminologia árabe. Ao se compararem com as personagens bíblicas, ou mesmo com religiosas de outras

13 Lapassade, 1991.

14 Oração islâmica em congregação às sextas-feiras.

15 Mesquita.

16 Retirado de http://www.mesquitadobras.org.br/?op=33 em 12/03/2014.

17 As interlocutoras pediram para não serem identificadas nominalmente, apenas pelas suas iniciais e trajetórias biográficas. 
denominações adeptas do 'véu', como as freiras, sempre me perguntavam: por que elas são religiosas e nós submissas? A comparação visa desconstruir o estereótipo, retirar a mácula, a ideia de submissão e sofrimento erroneamente atribuídas a essas mulheres. De fato, costumava responder que era ultrajante o estereótipo da mulher muçulmana, deveras infeliz e subjugada e citava as feministas islâmicas que construíam seus discursos baseando-se em uma leitura vanguardista do Qur'an. Dra Amina Wadud, Laila Abu Lughood e Fatima Mernissi são exemplos dessa nova retórica, mas, ainda pouco conhecidas da maioria dessas mulheres. Quando questionadas sobre suas ideias acerca da identidade feminina muçulmana, frequentemente, definiam seu lugar de fala como o de uma muçulmana modesta, lembrando-nos que as exigências de recato e pudor podem ser lidas no Alcorão na terceira surata' ${ }^{18}$ 'An Nissán'19. De acordo com essas mulheres, a total liberdade e autonomia vinham do uso do hijab que lhes garantia a possibilidade de serem reconhecidas intelectualmente, antes da apreciação de seus atributos físicos e que, assim, poderiam elevar sua autoestima e ter a certeza do sucesso profissional acompanhada de uma duradoura paz de espírito, pois antes de agradar os homens agradavam primeiro a Allah, como me relatou D. B. por diversas vezes. Através dos relatos a respeito da vida profissional dessas três mulheres, também pudemos analisar empiricamente o binômio geossímboloterritorialidade através de sua projeção sígnica hijab e corpo. A retórica bem fundamentada de satisfação pessoal, liberdade e obediência religiosa, graças ao uso do geossímbolo, é identificada pela exteriorização de poder, controle e exclusividade no cotidiano dessas mulheres, características próprias da territorialidade. Ora, se o geossímbolo (hijab) é simbolismo de determinada cultura (BONNEMAISON, 2005) e é por si só capaz de criar um território, delimitá-lo política e juridicamente, temos no cotidiano mulheres que instrumentalizam esse geossímbolo para conferir identidade, controle e exclusividade a seus corpos, ainda que a motivação seja majoritariamente religiosa. A proibição do uso do hijab, em seu local de trabalho, obrigou I. K., por direito e dever, a perseguir na lei brasileira uma indenização judicial para esse ato atentatório. $O$ corpo da mulher muçulmana, impregnado de simbolismo, encontra barreiras que devem ser transpostas por um direito a ter seu corpo exclusivamente enquadrado dentro das normas religiosas, tornandoo objeto de poder e influência, seja na exigência dos direitos fundamentais ou na garantia de ter sua identidade preservada e respeitada. A discussão geográfica sobre o assunto torna-se cada vez mais ampla à medida que novas situações, relatos e diálogos são desenvolvidos e analisados. Recortamos esses dois momentos dialógicos, justamente escolhidos por trazerem de maneira mais engendrada e coerente as questões geográficas em tela.

A tentativa, levada a cabo com êxito, concentrou-se em reunir três mulheres que têm o Islã como prática religiosa, no entanto, advém de culturas distintas e grupos sociais diversos. O que se pode comprovar com os discursos nos quais defendem o uso do hijab, é que a recompensa divina supera as possíveis

18 Capítulo. O Alcorão tem 114 suratas, ou 114 capítulos.

19 'As Mulheres'. 
instrumentalizações políticas que o hijab possa vir a ter. Isso confirma a ideia inicial, exposta no primeiro capítulo, de que o empoderamento feminino para as mulheres muçulmanas que usam o hijab advém da eficácia com que essa mulher constrói sua territorialidade através do geossímbolo religioso, retroalimentando sua identidade cultural e destruindo os estereótipos negativos no que diz respeito à mulher muçulmana, muito presentes no imaginário ocidental. Para tanto, é necessário que ela desenvolva sua agência nos espaços e lugares (TUAN, 1980) com autonomia.

Portanto, a apropriação cultural, dada no momento em que a muçulmana opta pelo uso do hijab, não traduz ou relaciona diretamente esta mulher a um habitus $^{20}$ similar ao Oriente Médio, tampouco estabelece uma correlação de padrões culturais reproduzíveis como legitimadores da inserção dessa mulher na religião ${ }^{21}$. A religião se espraia em diversos espaços e se apropria da cultura material ali desenvolvida, o que significa que o uso do hijab obedece a uma finalidade religiosa, no entanto, seu entendimento e apropriação sociocultural e política varia de acordo com o lugar. Em viagem ao Líbano, especialmente na capital Beirute, pudemos observar a estética do hijab, observada pela forma como o lenço é amarrado, traduzindo em qual grupo sectário a mulher se inclui. Zaiditas, alawuitas, sunitas e xiitas reproduzem suas identidades na amarração do hijab e em menor escala, em suas cores. Tal panorama com esta tipologia estética diversificada não pode ser observado no campo, valendo-se estas mulheres, tanto brasileiras revertidas quanto árabes descendentes, de novas apropriações e leituras do uso do hijab, entretanto, o significado teológico é imutável.

$\mathrm{O}$ que se pretende traçar aqui, para um melhor entendimento do contexto geográfico das vozes femininas do Islã, é o afastamento de maneira peremptória e definitiva entre a apropriação cultural - naturalmente vista nos fluxos dinâmicos entre culturas em dado ambiente, implicando no uso e na prática de costumes de outros grupos sem uma finalidade de conexão com o sagrado - e o exercício da religião, que podem ser traduzidos em duas materialidades distintas em seu significado: símbolo religioso e artefato cultural. O hijab é compreendido tanto literalmente em sua etimologia quando da sua tradução no capítulo anterior, através das fontes sagradas do Islã - quanto no campo, nos discursos e nas performances como um símbolo diretamente relacionado ao Islã.

A mulher muçulmana, por sua vez, cabem tantas mulheres e tantas muçulmanas, tantos discursos e tantas outras corporalidades, que não podemos universalizá-la. [...] As diferenças que as separam são também as que as unem, na medida em que, cada qual a seu modo, buscam a melhoria de suas condições sociais, criticando a interpretação patriarcal dos escritos corânicos, propondo, assim, uma nova leitura do Alcorão, implicando, muitas vezes, em uma (re)leitura

20 Conceito de Bordieu, entendido como: disposições duráveis, capacidades treinadas, e modos de pensar, agir e sentir.

21 Religião entendida como "um sistema de símbolos estruturados" (GEERTZ, 2000, p.104). 
Hijab e Identidade: as Formas de Empoderamento Feminino Através da

Territorialização do corpo no Islã

de si mesmas (BAUMANN, 2013, p. 127-128).

Usar o hijab no espaço público não islâmico é, antes de um acato à norma religiosa, uma performance do sagrado, a construção de sua territorialidade, uma retroalimentação da identidade, é a hierocracia ${ }^{22}$ em sua manifestação mais extensiva.

\section{Conclusão}

A desconstrução de estereótipos perpassa uma correta compreensão do contexto cultural do grupo social analisado. Os conceitos utilizados aqui visam a uma releitura do feminismo religioso islâmico sob uma base científica que, naturalmente, legitima as análises apresentadas. Há uma gama de questões ainda a serem analisadas relacionadas à sexualidade, poder, territórios/territorialidades religiosas, hierarquia e parentesco. Cabe um desdobramento pontual e contextualizado para não incorrermos no erro do julgamento dos sentidos, sem a compreensão aprofundada das diversas modalidades de agência feminina na contemporaneidade. A religião, foco desta análise, é constantemente deslocada de seu senso comum para áreas antes inexploradas, como a antropologia da performance e a Geografia Humana, que veio a reboque das novas inquietações no estudo do espaço e contribuiu significativamente para uma apreensão completa do fenômeno religioso em sua amplitude e complexidade.

A tentativa levada a cabo, de analisar os conceitos geográficos em decorrência de suas projeções sígnicas, resultou na possibilidade de ampliar o debate das relações de gênero a partir da ciência geográfica, para que possamos empreender reflexões e ações práticas influentes na modificação de pensamentos e no stablishment do ideário patriarcal.

Que as novas considerações e releituras, aqui propostas, sejam apenas o ensejo para uma abrangência científica maior e contínua para o estudo geográfico acerca da religião e gênero e suas interfaces.

\section{Referências}

AHMED, L. Woman and Gender in Islam. Yale: Yale University Press, 1992.

ARROYO, K. Majlis de Ashura: Territórios de Performance. Revista Litteris, v. 1, n. 17, p. $67-71,2016$.

ARROYO, K. A construção de um território religioso móvel no Brasil: Islam, Identidades e Simbolismo. Revista Espaço e Cultura, v. 1, n. 37, p. 6 - 25, 2015.

ARROYO, K. As espacialidades islâmicas xiitas:os geossímbolos na construção de uma identidade particular. Caderno de Geografia, v. 26, n. 45, p. $1-10,2014$.

22 Poder do Sagrado. 
Hijab e Identidade: as Formas de Empoderamento Feminino Através da

Territorialização do corpo no Islã

ARROYO, K. Ashura: o ritual de construção do luto na cidade de São Paulo. Caderno do Núcleo de Análises Urbanas - CaderNAU, v. 7, n. 1, p. 141153, 2014.

AGROSINO, M. Etnografia e observação participante. Porto Alegre: Artmed, 2008.

BADRAN, M. Feminism in Islam: Secular and Religious Convergences. London: Oneworld Publication, 2009.

BAUMANN, L.. A corporalidade do recato-Mulheres Muçulmanas, seus corpos e seus discursos. Revista de Estudos da Religião (REVER), v. 13, n. 1, p. 113-129, 2013.

BONNEMAISON, J. Culture and Space: Conceiving a New Geography. London: I.B Tauris e Co Ltd, 2005.

BORDIEU, P. O Poder Simbólico. Rio de Janeiro: Bertrand, 1998.

BORDIEU, P. A dominação masculina. Rio de Janeiro: Bertrand Brasil, 2003.

CASTRO, C. M. de. Muçulmanas no Brasil: reflexões sobre a relação entre religião e dominação de gênero. Mandrágora, v. 14, n. 14, p. 80 - 96, 2009.

CÔRREA, R. L; ROSENDAHL, Z. Religião, Identidade e Território. In: CÔRREA, R. L; ROSENDAHL, Z. (Org.) Geografia Cultural: Uma Antologia. Rio de Janeiro: EdUERJ, 2012.

DA MATTA, R. Relativizando. Uma introdução à Antropologia Social. Petrópolis: Vozes, 1981.

GEERTZ, C. O saber local: novos ensaios em antropologia interpretativa. Trad: Vera Mello Joscelyne. Petrópolis: Vozes, 1997.

GOFFMAN, E. Estigma-Notas sobre a Manipulação da Identidade deteriorada. Rio de Janeiro: Zahar Editores, 1980.

GOFFMAN, E. A Representação do Eu na Vida Cotidiana. New York: Hangdon House, 2006.

HAESBAERT, R. Identidades Territoriais. In: ROSENDAHL, Z.; CÔRREA, R. L; Geografia Cultural: Uma antologia. Volume II. Rio de Janeiro: EdUERJ, 2013, p. 233 - 244.

HAESBAERT, R. O mito da desterritorialização: do fim dos territórios à multiterritorialidade. Rio de Janeiro: Bertrand Brasil, 2006.

HALL, S. Da diáspora: identidades e mediações culturais. Belo Horizonte: Editora UFMG, 2006. 
Hijab e Identidade: as Formas de Empoderamento Feminino Através da

Territorialização do corpo no Islã

HALL. E. A dimensão oculta. São Paulo: Martins Fontes, 2005.

HAMMERSLEY, M. Reading Ethnographic Research: A Critical Guide. London: Longman, 1990.

HOLZER, W. A Geografia Humanista: Uma revisão. Revista Espaço e Cultura, edição Comemorativa, p.137-147, 2008.

LAPASSADE, G. L' Éthnosociologie. Paris: Méridiens Klincksieck, 1991.

LIMA, C. Um recente movimento político-religioso: feminismo islâmico. Revista Estudos Feministas, v. 22, n. 2, p. 675 - 686, 2014.

LUGHOOD, L. Remaking Woman: Feminism and Modernity in the Middle East. New Jersey: Princeton University Press, 1998.

MAcGINTY, A. Emotional geographies of veiling: the meanings of the hijab for five Palestinian American Muslim women. Gender, Place and Culture, v. 21, n. 6, p. 683-700, 2014.

MAIA, C. E. S. Geografia das Vestimentas: dos clássicos às tendências. Boletim Goiano de Geografia, v. 35, n. 2, p 195 - 216, 2015.

MAGNANI, J. G. C.. De perto e de dentro: notas para uma etnografia urbana. Revista Brasileira de Ciências Sociais, v. 17,n. 49, p 11 - 29, 2002.

MAHMOOD, S. The politics of Piety: The Islamic Revival and the Feminism Subject. Princeton: Princeton University Press, 2005.

MALUF, S. Corpo e corporalidade nas culturas contemporâneas: abordagens antropológicas. Revista Esboços, v. 9, n. 9, p. 87 - 101, 2001.

MAUSS, M. As técnicas corporais. Sociologia e Antropologia, v. 2, p 209233, 1974.

MERNISSI, F. Beyond the Veil: Male-female Dynamics in Modern Muslim Society. Bloomington: Indiana University Press, 1987.

MERNISSI, F. Le Harem politique: Le prophete et les femmes. Par M'hammoud Mellouki. Recherches Féministes, v. 4, n. 2, p. 159-164, 1991.

MERNISSI, F. The veil and the male elite: a feminist interpretation of women's rights in Islam. Nova York: Perseus Group, 1991.

MORAES, E. O Corpo Impossível - a decomposição da figura humana: de Lautréamont a Battaile. São Paulo: Iluminuras, 2002.

MOSCOVICI, S. Representações sociais: investigações em psicologia social. Trad. Pedrinho A. Guareschi Petrópolis, RJ: Vozes, 2003.

MOTAHARI, A. Os Direitos das Mulheres no Islam. Trad. Al Qalam. São Karina Cruz Arroyo 
Hijab e Identidade: as Formas de Empoderamento Feminino Através da

Territorialização do corpo no Islã

Paulo: Arresala, 2008.

NORTON, W. Cultural Geography: Themes, Concepts, Analysis. Oxford: Oxford University Press, 2000.

PINTO, C. R. J. Quem tem direito ao uso do véu - uma contribuição para pensar a questão brasileira. Cadernos Pagu, n. 26, p. 377-403, 2006.

PINTO, P. G. Islã: Religião e Civilização - Uma abordagem Antropológica. Aparecida: Santuário, 2010.

RAFFESTIN, C. Por uma Geografia do poder. São Paulo: Àtica, 1993.

ROSE, G. Feminism and Geography: The limits of Geographical Knowlwdge. Cambridge: Polity Press, 1993.

ROSENDAHL, Z; CORREAA, R. L. (Orgs). Religião, Identidade e Território. Rio de Janeiro: EdUERJ, 2001.

ROSENDAHL, Z. Território e Territorialidade: uma perspectiva geográfica para o estudo da religião. Anais do $\mathrm{X}$ Encontro de Geógrafos da América Latina. Universidade de São Paulo (USP), São Paulo, 20 a 26 de março de 2005.

SACK, R. The human territoriality - its theory and history. Cambridge, Cambridge University Press, 1986.

SCHECHNER, R. What is performance. In: BRADY, S.. Performance studies: an introduccion, second edition. New York \& London: Routledge, 2006, p. 28-51.

SCHECHNER, R. By Means of Performance. Cambridge: Cambridge University Press, 1990.

SCHECHNER, R. The future of Ritual: writings on culture and performance. Nova York: Routledge, 1995.

SILVA, J. M. (Org). Geografias Subversivas: discursos sobre espaço, gênero e sexualidades. Ponta Grossa: Toda Palavra Editora, 2009.

SILVA, J. M. Geografia e Gênero no Brasil; uma análise da feminização do campo científico. Revista Ateliê Geográfico, v. 3, n. 2, p. 38 - 63, 2009.

SOJA, E. W. The political Organization of Space. Washington, D.C: AAG Comission on College Geography, 1971.

TABATABAÍ, A. O Alcorão no Islam. Trad. Ismail Andrade Barbosa. São Paulo: Arresala, 2012.

TUAN, Yi-Fu. Espaço e lugar: a perspectiva da experiência. São Paulo: 
Hijab e Identidade: as Formas de Empoderamento Feminino Através da

Territorialização do corpo no Islã

Difel, 1983.

TUAN, Yi-Fu. Topofilia - Um estudo da percepção, atitudes e valores do meio ambiente. Londrina: EDUEL, 2012.

TRUZZI, O. M. S. De mascates a Doutores: Sírios e libaneses em São Paulo. São Paulo: HICITEC, 1997.

VERSIANI, D. B. Autoetnografias: conceitos alternativos em construção. Rio de Janeiro: 7Letras, 2005.

WADUD, A. Inside The Gender Jihad: Women's Reform in Islam. London: Oneworld Publication, 2013. 